\section{Will Any Amount of Original Research Truly Improve End-of-Life Decision Making for Critically III Elderly Patients?}

\section{Abstract}

Purpose: To review the manuscript: "Outcomes of critically ill medical and surgical patients: A multicenter cohort study", in order to evaluate its clinical utility for goals of care discussions prior to ICU admission.

Methods: A commentary by the author on the strengths, weaknesses and clinical applicability of this manuscript, as well as the body of literature that attempts to aid prognostication for critically ill elderly patients.

Conclusion: Clinicians who are regularly tasked with guiding substitute decision makers during end of life care discussions should incorporate their clinical opinion, patient's previously expressed wishes and results from applicable clinical studies, into their recommendations.

\section{Ian M Ball \\ Department of Medicine and Department of Epidemiology and Biostatistics, Western University, Canada}

\section{Corresponding author: Ian M Ball}

”Ian.Ball@Ihsc.on.ca

MD, MSc, Department of Medicine and Department of Epidemiology and Biostatistics, Western University, Ontario, Canada.

Citation: Ball IM. Will Any Amount of Original Research Truly Improve End-ofLife Decision Making for Critically III Elderly Patients? J Intensive \& Crit Care 2017, 3:2.

Received: May 11, 2017; Accepted: May 15, 2017; Published: May 22, 2017

\section{Introduction}

Not long ago, it was remarkable to admit a patient over 80 years of age to a Canadian Intensive Care Unit (ICU). Nowadays, it is commonplace to admit patients in their ninth and tenth decades of life. Is this change in practice helping patients? Are very elderly patients being cured of their critical illnesses and returning home to meaningful quality of lives? Or is the current system violating patient autonomy, stripping patients of dignity and humanity, and prolonging their deaths, at the peril of our publicly funded health care system?

Our recent manuscript published in the Canadian Journal of Anesthesia [1] was a sub study of Realistic 80 [2] (Realities, Expectations, and Attitudes to Life Support Technologies in Intensive Care for Octogenarians, clinicaltrials.gov NCT01293708), a multicenter prospective observational cohort study conducted in 22 Canadian academic and community ICUs from September 2009 to February 2013. Our primary objective was to describe the cohort outcomes, including ICU length of stay, ICU mortality, hospital length of stay, hospital mortality and participant's ability to return to their pre-ICU admission living environment.

\section{Elderly Patients Value Quality over Quantity of Life}

A high quality goal of care discussion should always occur prior of data that elderly patients would prefer to be cared for and to die in their own homes [3-5] and value quality over quantity of life-preferring to avoid technology-supported life prolonging measures [6]; increasing numbers of elderly patients are dying in ICUs $[3,7,8]$. There is a significant disconnect between the wishes of critically ill elderly patients and the care that they receive. Surely physicians are able to provide accurate diagnoses to inform decision making?

\section{Adjusting ICU Prognoses for Patient Age is Imperfect}

Is it inappropriate to admit a very old patient to the ICU? The answer to that question is it depends. In cases where the patient (or their substitute decision maker) is making an informed decision to undergo life sustaining therapy and the prognosis is good and known to be acceptable to the patient; patients must be admitted. It would be paternalistic to deny admission.

Unfortunately, the situation is rarely so clear. While it is known that elderly ICU patients can have very good outcomes [9-13], the evidence in this area is conflicted [14-19].

\section{Clinical Prediction Modeling is Imprecise}

Despite advances in the science of prediction modeling, and the recent publication of tools to address the very specific question 
we are asking [20], the derivation of such tools is frought with challenges. Perhaps the most insurmountable is the dynamic nature of ICU care. Over the past two decades, the bulk of critical care interventional trials have been negative, yet acuity adjusted outcomes continue to improve. Even the most methodologically sound mortality prediction models serve only as a means of improving physician judgment and increasing the objectivity of prognostication, due to the model's inability to adapt to changes in practice, and the implicit imprecision of trying to predict mortality. Practically, predictions of very high survival, or very high mortality, likely influence decision making to a greater extent than even the most accurate predictions of outcomes of intermediate probability. I.e. Predicting a 50\% ICU mortality, even with great accuracy, is not as likely to sway end-of-life decision making as a more extreme prognosis.

\section{All Prognostication Literature about Critically III Elderly will Suffer from Selection Bias}

It seems likely that one of the strongest factors influencing outcomes in prognostication studies in critically ill elderly patients is the participant selection process. A spectrum of care aggressivity exists; from residential palliation at one end, to emergent transfer to hospital for life sustaining therapy at the other. The degree of intervention may reflect patient values, family values or in more paternalistic environments, care team values. A study conducted in an ICU where only patients expected to survive are admitted, will demonstrate very different outcomes than ICUs with more liberal admission criteria.

\section{Barely Half of All Medical and Surgical Patients Returned Home}

Despite many of the challenges discussed above, as well as others reviewed in the manuscript, less than half of medical and surgical patients in our cohort were able to return home. Many elderly patients would likely not consider hospital discharge to a chronic care facility to live in a state of dependency as an acceptable quality of life. Even without using an individualized clinical prediction model [20], a description of the median duration of life support, hospital length of stay and percent of all survivors able to return home, would likely add an important dimension to most goals of care discussions prior to ICU admission.

\section{Conclusion}

Despite the great improvements in the volume and quality of end of life prognostication research, this area of literature can only serve to inform high quality goals of care discussions, not drive them. That said, there is little doubt that expert opinion and excellent communication is improved by the incorporation of robust prognostication research into day to day clinical decision making. 


\section{References}

1 Ball IM, Bagshaw SM, Burns KE, Cook DJ, Day AG, et al. (2017) Outcomes of elderly critically ill medical and surgical patients: A multicenter cohort study. Can J Anesth 64: 260-269.

2 Heyland D, Cook D, Bagshaw SM, Garland A, Stelfox HT, et al. (2015) The very elderly admitted to ICU: A quality finish? Crit Care Med 43: 1352-1360.

3 Baker R, Wu AW, Teno JM, Kreling B, Damiano AM, et al. (2000) Family satisfaction with end-of-life care in seriously ill hospitalized adults. J Am Geriatr Soc 48: S61-S69.

4 Angus DC, Kelley MA, Schmitz RJ, White A, Popovich J Jr (2006) Caring for the critically ill patient. Current and projected workforce requirements for care of the critically ill and patients with pulmonary disease: Can we meet the requirements of an aging population? JAMA 284: 2762-2770.

5 Marik PE (2006) Management of the critically ill geriatric patient. Crit Care Med 34: S176-S182.

6 Heyland DK, Dodek P, Rocker G, Groll D, Gafni A, et al. (2006) What matters most in end-of-life care: Perceptions of seriously ill patients and their family members. CMAJ 174: 627-633.

7 Council on Scientific Affairs, American Medical Association (1996) Good care of the dying patient. JAMA 275: 474-478.

8 Williams TA, Dobb GJ, Finn JC, Knuiman MW, Geelhoed E, et al. (2008) Determinants of long-term survival after intensive care. Crit Care Med 36: 1523-1530.

9 Chalfin DB, Carlon GC (1990) Age and utilization of intensive care unit resources of critically ill cancer patients. Crit Care Med 18: 694698.

10 Fedullo AJ, Swinburne AJ (1983) Relationship of patient age to cost and survival in a medical ICU. Crit Care Med 11: 155-159.
11 Garrouste-Org, Boumendil A, Pateron D, Aergerter P, Somme D, et al. (2009) Selection of intensive care unit admission criteria for patients aged 80 years and over and compliance of emergency and intensive care unit physicians with the selected criteria: An observational, multicenter, prospective study. Crit Care Med 37: 2919-2928.

12 Wu AW, Rubin HR, Rosen MJ (1990) Are elderly people less responsive to intensive care? J Am Geriatr Soc 38: 621-627.

13 Alexander KP, Anstrom KJ, Muhlbaier LH, Grosswald RD, Smith PK, et al. (2000) Outcomes of cardiac surgery in patients $>$ or $=80$ years: Results from the National cardiovascular network. J Am Coll Cardiol 35: 731-738.

14 Carson SS, Garrett J, Hanson LC, Lanier J, Govert J, et al. (2008) A prognostic model for one-year mortality in patients requiring prolonged mechanical ventilation. Crit Care Med 36: 2061-2069.

15 Nathanson BH, Higgins TI, Brennan MJ, Kramer AA, Stark M, et al. (2011) Do elderly patients fare well in the ICU? Chest 139: 825-831.

16 Niskanen M, Kari A, Halonen P (1996) Five-year survival after intensive care comparison of 12,180 patients with the general population. Finnish ICU study group. Crit Care Med 24: 1962-1967.

17 Rady MY, Johnson DJ (2004) Hospital discharge to care facility: a patient-centered outcome for the evaluation of intensive care for octogenarians. Chest 126: 1583-1591.

18 Williams TA, Dobb GJ, Finn JC, Knuiman MW, Geelhoed E, et al. (2008) Determinants of long-term survival after intensive care. Crit Care Med 36: 1523-1530.

19 Wright JC, Plenderleith L, Ridley SA (2003) Long-term survival following intensive care: Subgroup analysis and comparison with the general population. Anaesthesia 58: 637-642.

20 Ball IM, Bagshaw SM, Burns KEA, Cook DJ, Day AJ, et al. (2016) A clinical prediction tool for hospital mortality in critically ill elderly patients. J Crit Care 35: 206-212. 